\title{
Quiz: Echo imaging
}

\section{Case}

A 55 years old male patient with severe coronary artery disease was sent to our echocardiography lab for preoperative evaluation. Figure 1 and 2 were taken from his echo recordings (video 1 and 2). What is the differential diagnosis in such picture?
A. A dilated aortic root
B. A dilated coronary sinus with possible persistent left superior vena cava
C. Ostium primum atrial septal defect
D. A flail mitral valve

Zehra Ilke Akyildiz ${ }^{1}$, Oben Baysan ${ }^{2}$ ${ }^{1}$ Private Cardiology Clinic, İzmir, Turkey

${ }^{2}$ Guven Hospital, Ankara, Turkey

Peer-review: Internal and external Conflict of interest: None to declare Authorship: Z.I.A, O.B. are equally contributed to management of case and preparation of article Acknowledgement and funding: None to declare

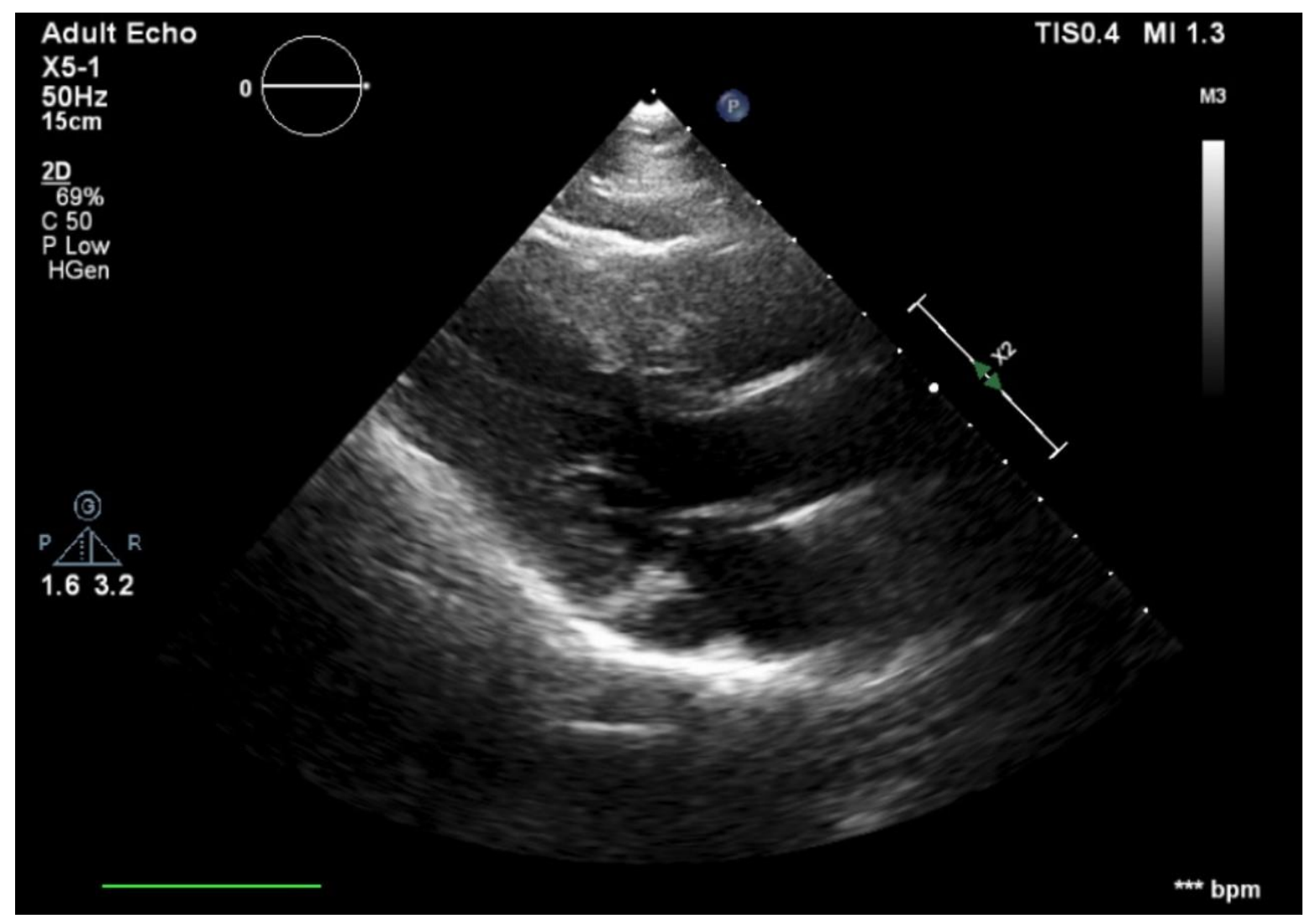

Figure 1. Echocardiographic image

Video 1. Echocardiographic images

Address for Correspondence: Ilke Zehra Akyildiz, Izmir, Turkey Email: ziakyildiz@hotmail.com

Received: 13.11.2020 Revised: 06.12.2020 Accepted: 06.12.2020

Copyright @2020 Heart, Vessels and Transplantation 
Heart, Vessels and Transplantation 2020; 4: doi: 10.24969/hvt.2020.227

Echo quiz

Akyildiz et al.

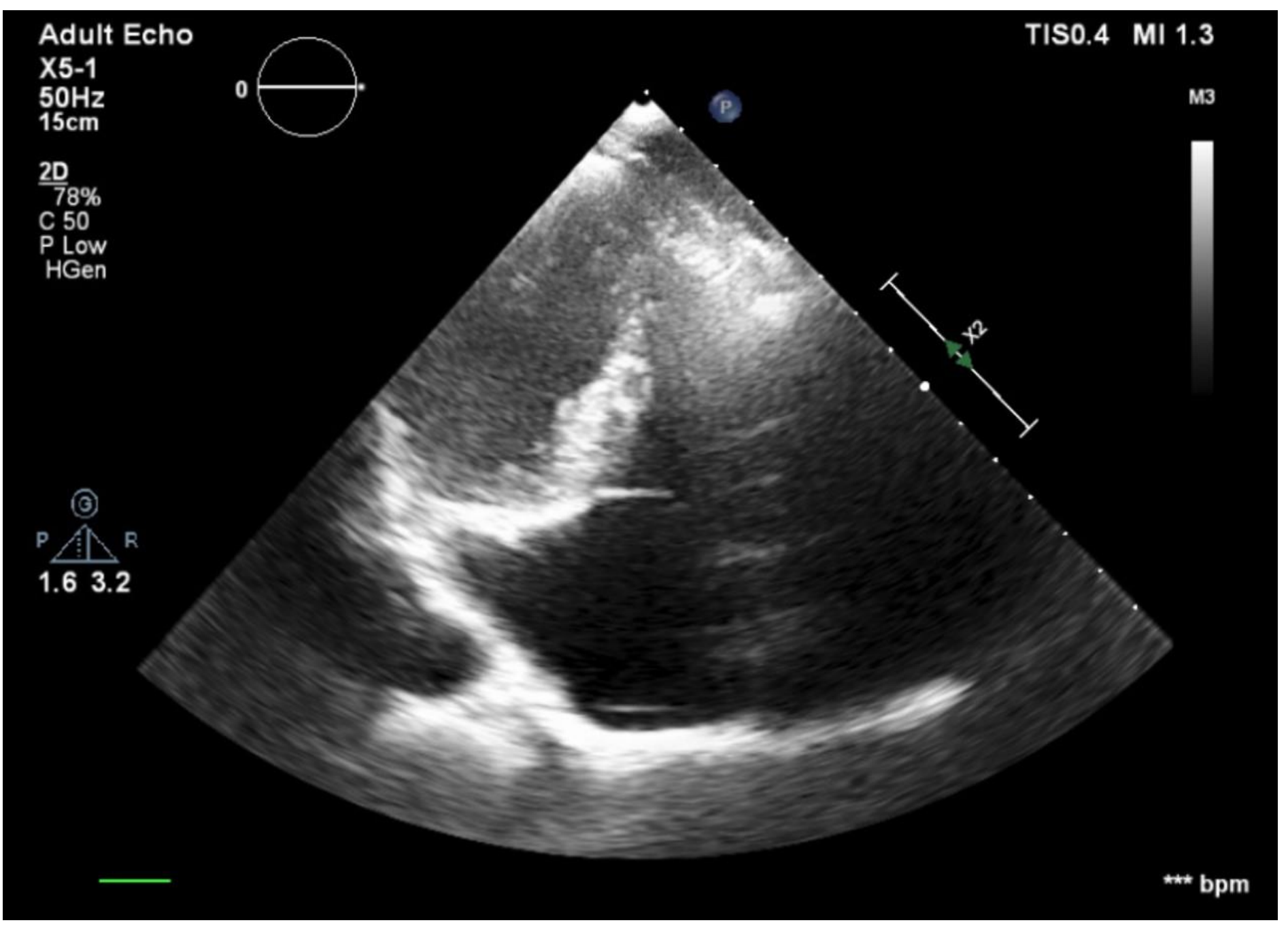

Figure 2. Echocardiographic image Video 2. Echocardiographic images 